\title{
PROCEEDINGS OF THE SOCIETY OF PUBLIC ANALYSTS.
}

\author{
ON CHICORY, AND VARIATIONS IN ITS COMPOSITION. \\ By Bernard Dyer, D.Sc. \\ (Read at the Meeting, June 1, 1898.)
}

Dischepancies between analysts in estimating the proportion of chicory in mixtures of chicory and coffee appear to be unfortunately frequent, and these may be attributed to varying assumptions as to the composition of the chicory present. As there is no satisfactory mode of separating coffee and chicory, the analyst is driven to base his calculations mainly upon the proportion of soluble matter in the sample, and on the assumed average proportions of soluble matter in coffee and chicory. Most analysts experimentally deduce their estimate of soluble matter, and hence the proportions of coffee and chicory, from the density of 10 per cent. infusion of the mixture, and a great many data are on record of the densities of such infusions of coffee and of chicory, but most of them are old. Some analysts-E. W. T. Jones, for exampleprefer to evaporate a measured portion of the watery extract and actually weigh the soluble residue. Alfred Smetham in 1883 (ANALYst, vii., 73) suggested thoroughly boiling out the sample with water, washing, drying, and weighing the insoluble residue on a counterpoised filter. It presumably makes but little difference which method is used, provided that the same mode of working is adopted for comparative purposes ; but, as since the publication of Mr. Smetham's paper, I have myself always determined the insoluble matter directly, and the soluble matter by difference, it is in this form that $I$ now propose to record some results of a recent investigation into the composition of the chicory at present in the market.

Mr. Bannister, in his evidence before the late Select Committee on Food Products Adulteration, in reply to a question from Sir Charles Cameron, endorsed an experience, attributed to Mr. Hehner, to the effect that the soluble matter in chicory appeared to have increased during the last ten or fifteen years, a fact which Mr. Bannister attributed to "difference of growth." My own experience confirms that of Mr. Hehner and Mr. Bannister, but I think there is no reason to suppose that the difference is due to methods of growth. It is more easily and probably accounted for by a custom of less highly roasting.

In 1883 I examined six samples of chicory obtained from various sources, with a view to their being representative of the chicory then in the market, and found that, calculated on the samples dried at $212^{\circ} \mathrm{F}$., the matter insoluble in water, after exhaustively boiling and washing, weighed on the average 33 per cent., the variations being from a little over 30 to a little over 36 . In 1895 I had occasion to examine a sample of chicory stated to be representative of that which was in use by a very large firm of wholesale grocers, and found only 22 per cent. of insoluble matter in the dried sample.

During the present year I took steps to obtain from several thoroughly representative wholesale houses samples of the chicory in current use, in all cases requesting to be supplied with samples representing any different grades of roasting or colour 
that might be in current use. It may be stated that the percentage of moisture varied in extreme cases from 1 per cent. to 4 per cent., but the following results are all calculated on the dry substance. They show the total matter insoluble in water (inclusive of mineral matters), the ether extract, the nitrogen, the total ash, the ash soluble in water, and the sand.

\begin{tabular}{|c|c|c|c|c|c|c|c|c|c|}
\hline & $\begin{array}{c}\text { Total } \\
\text { Matter } \\
\text { Insoluble } \\
\text { in } \\
\text { Water. }\end{array}$ & $\begin{array}{c}\text { Ether } \\
\text { Extract. }\end{array}$ & Nitrogen. & $\begin{array}{l}\text { Total } \\
\text { Ash. }\end{array}$ & $\begin{array}{c}\text { Ash } \\
\text { Soluble in } \\
\text { Water. }\end{array}$ & Sand. \\
\hline \multirow{2}{*}{\multicolumn{4}{|c|}{$\begin{array}{l}\text { Chicory " nibs," described } \\
\text { as "medium roast" }\end{array}$}} & Per cent. & Per cent. & Per cent. & Per cent. & Per cent. & Per cent. \\
\hline $\begin{array}{r}\text { as } \\
\text { Chico }\end{array}$ & & & & $22 \cdot 40$ & 2.57 & 1.53 & 463 & $2 \cdot 50$ & $0 \cdot 70$ \\
\hline \multicolumn{4}{|c|}{$\begin{array}{c}\text { Chicory " nibs," described } \\
\text { as "dark roast" }\end{array}$} & $50 \cdot 30$ & $2 \cdot 43$ & $1 \cdot 67$ & $4 \cdot 70$ & 299 & $0 \cdot 30$ \\
\hline \multicolumn{2}{|c|}{ Ground chicory } & $\ldots$ & $\ldots$ & $22 \cdot 27$ & $2 \cdot 17$ & $1 \cdot 33$ & $5 \cdot 53$ & $2 \cdot 43$ & $1 \cdot 43$ \\
\hline , &, & $\ldots$ & $\ldots$ & $21 \cdot 50$ & $1 \cdot 90$ & $1 \cdot 34$ & $5 \cdot 23$ & $2 \cdot 07$ & $1 \cdot 43$ \\
\hline , & ", & $\ldots$ & $\ldots$ & $35 \cdot 50$ & $3 \cdot 43$ & $1 \cdot 50$ & $5 \cdot 13$ & $2 \cdot 57$ & $0 \cdot 77$ \\
\hline ", & ," & $\ldots$ & $\ldots$ & $37 \cdot 80$ & $3 \cdot 87$ & $1 \cdot 52$ & $8 \cdot 23$ & $1 \cdot 60$ & $3 \cdot 97$ \\
\hline ," & ," & $\ldots$ & $\ldots$ & $22 \cdot 77$ & $3 \cdot 17$ & $1 \cdot 25$ & $5 \cdot 13$ & $3 \cdot 30$ & $1 \cdot 60$ \\
\hline , & , & $\ldots$ & $\ldots$ & $22 \cdot 50$ & $3 \cdot 67$ & $1 \cdot 23$ & $5 \cdot 73$ & $3 \cdot 23$ & $1 \cdot 63$ \\
\hline ", & ," & $\ldots$ & $\ldots$ & $23 \cdot 50$ & $2 \cdot 60$ & $1 \cdot 29$ & $5 \cdot 63$ & $2 \cdot 97$ & $1 \cdot 47$ \\
\hline , & ," & $\ldots$ & .. & $22 \cdot 50$ & $2 \cdot 60$ & $1 \cdot 29$ & $5 \cdot 33$ & $3 \cdot 20$ & $1 \cdot 47$ \\
\hline , & ," & $\ldots$ & $\ldots$ & $22 \cdot 63$ & 2.57 & $1 \cdot 29$ & $5 \cdot 70$ & $2 \cdot 60$ & 1.47 \\
\hline
\end{tabular}

It will be seen that in eight out of the eleven samples the matter insoluble in water ranged from 21.50 to 23.50 per cent. One sample contained 35.50 per cent., one $37 \cdot 80$, and one $50 \cdot 30$ per cent. of insoluble matter.

I have myself made no experiments to ascertain what percentage of insoluble matter is indirectly indicated by the figures usually assumed to represent the specific gravity of a 10 per cent. infusion of chicory, but $I$ believe they may be taken as roughly corresponding to about 70 per cent. of soluble matter and 30 per cent. of insoluble matter, corresponding to the 70 per cent. of soluble matter assumed by E. W. T. Jones as representing chicory in his direct method of determination.

There is no doubt that, if the samples I have recently obtained fairly represent the chicory at present in the market-and I have every reason to think they do-any estimates deduced from density determinations with the aid of the older data would result in too high an estimate of the proportion of chicory, since they assume a much less proportion of soluble matter than that which is present in the greater part of the chicory at present in use. It is quite true, on the other hand, that with some kinds of chicory at present in use, reliance on the old figures might cause an error on the side of considerably underestimating the proportion of chicory ; but an underestimate of the inferior article is, from the public analyst's point of view, obviously a matter of far less moment than an overestimate, which would reflect unjustly upon a seller of the article. It is indeed remarkable that, after attention had been drawn to the matter, the old figures should have still remained in use.

The following experiments were made with the sample marked "chicory nibs, medium roast," which gave originally 22.40 per cent. of insoluble matter. A portion 
of the sample, after grinding and drying, was placed in a platinum capsule over a very low argand flame, and gently heated with thorough stirring until it had lost about 5 per cent. of its weight. A similar portion was similarly treated until it had lost about 10 per cent. of its weight. Calculating on the original weight taken, the proportion of insoluble matter in the first experiment rose from its original figure of 22.40 per cent. to 28.50 per cent., and during the second experiment it rose to 41.50 per cent. Seeing that there was a loss in the two experiments of 5 and 10 per cent. respectively, the percentage of insoluble matter in the actual roasted chicories would be 30 per cent. as the result of the first experiment, and 46 per cent. as the result of the second experiment. In neither case was there any appearance which could be described as that of burning. It seems clear, therefore, that the percentage of insoluble matter is mainly a function of the mode and duration of roasting.

It may be of moment to mention here that, on exhaustive boiling, Smetham, in 1882 , found a number of coffee samples to contain about 75 per cent. of matter insoluble in water. Three samples of coffee of known purity which I examined in 1883 by this method gave from 72 to 73.3 per cent., averaging 72.9 . In 1895 I made determinations in a batch of 16 samples of pure coffee, which showed a range of from $69 \cdot 4$ to 74.3 per cent., averaging 72 per cent. In 1897,27 pure samples ranged from 71.8 to 75.9 per cent., averaging 73.7 per cent. I have found as little as somewhat over 68 per cent. of insoluble matter (on the dry sample) in a ground coffee in which no chicory was discernible, and which on all other grounds appeared to be genuine; but it is quite possible that in this, as in some other cases somewhat approximating to it, sugar may have been used in roasting the coffee, though no evidence was obtainable that such was the case.

\section{Discussion.}

Mr. Cassal said that quite five years previously he had found as much as 79 per cent. of soluble matter in chicory, and had in consequence been in the habit of depending upon the number 79, which almost exactly corresponded with the minimum figure now given by Dr. Dyer for insoluble matter, viz., 21.5 per cent. With regard to the samples yielding 50.3 and 37.8 per cent. of insoluble matter, it was evident that such cases were altogether abnormal, and that what could properly be regarded as "chicory" was not being dealt with. In a substance like chicory, continued roasting necessarily increased the proportion of insoluble matter.

Mr. Chattaway inquired whether the tinctorial power increased as the roasting was carried to a higher degree. A highly caramelized sample might be expected to yield a darker solution than one that has been less highly roasted.

$\mathrm{Mr}$. Chapman observed that the relative proportions of soluble and insoluble matters would depend to some extent, not only upon the actual temperature, but also upon the conditions under which the roasting process was carried on. In roasting a substance like chicory, containing all kinds of caramelizable bodies, soluble compounds would be formed up to a certain point, after which such soluble compounds would to some extent be decomposed, with the result that the soluble matter, after reaching a maximum, would diminish again. In the manufacture of caramel from sugar, if the heating were effected too quickly, or the caramelized sugar poured into water at 
too early a stage in the process, the maximum coloring power and soluble extract would not be obtained. It was, he thought, to be expected that considerable variations from what might be called the normal extract should from time to time be observed.

Mr. CASSAL added that he thought the figure usually taken for soluble matter in pure coffee, viz., 24 per cent., was sometimes, too easily accepted. He had himself found as much as 29 per cent. of soluble matter in genuine coffee.

Dr. Dyer said that he had once found 68 per cent. of soluble matter in a sample of coffee that was undoubtedly free from chicory. The sample, however, might have been roasted with sugar, and this was difficult to detect.

Dr. VoELcker asked how much oil chicory usually contained.

Dr. Dyen said that the oil was from 2 to $3 \frac{1}{2}$ per cent., but it did not seem to have any relation to the other constituents. In the sample containing 50 per cent. of insoluble matter the oil was $2 \frac{1}{2}$ per cent. ; in the two lowest samples it was $2 \frac{1}{2}$ and $3 \frac{1}{2}$ per cent. respectively. The highly roasted samples were somewhat darker than the others, but in the case of a mixture the colour of the coffee itself would also be liable to variation. 